КРАСИНА Евгения Александровна - старший преподаватель кафедры английского языка факультета мировой экономики Дипломатической академии МИД России (119021, Россия, г. Москва, ул. Остоженка, 53/2, cmp. 1; lizza-sun@таil.ru)

\title{
АМЕРИКАНСКИЕ ГОРКИ ДЛЯ РОССИИ: ВЫСТОЯТЬ СРЕДИ ВНЕШНИХ И, ГЛАВНОЕ, ВНУТРЕННИХ УГРОЗ
}

Аннотация. Соглашательская внешняя и катастрофическая внутренняя экономическая политика руководства СССР, а затем и России привели к значительному сокращению населения, а само государство поставили в очередь на разрушение Североатлантическим альянсом во главе с США по югославскому сценарию. Прямолинейно унижающая политика Запада показала новому руководству России, желавшему равноправного сотрудничества во всех сферах, отсутствие стремления Запада идти навстречу. Ответом на приближение НАТО к границам России стала реформа вооруженных сил, проведенная так результативно, что позволила помочь Крыму вернуться в состав государства, а также союзной Сирии добиться успехов в борьбе с агрессией международного терроризма, поддерживаемого США. Однако внутренний враг, на стороне которого играют ошибки руководства, коррупция, вседозволенность чиновников, сращивание властей с криминалом и т.П., - самый опасный, о чем свидетельствует вся Новейшая история России. А значит, важно не давать поводов для подпитки лжезащитников народа России неприглядными фактами и, главное, восстанавливать социальную справедливость и обеспечивать население хорошо оплачиваемым квалифицированным трудом.

Ключевые слова: политика предательства интересов России, экономика России, агрессивная политика Запада, НАТО, стратегия обороны и развития России

$\Pi$ редательство элит Советского Союза, и затем России в 1990-х привело к беспрецедентной сдаче Западу всех завоеванных и добытых самоотверженным трудом всего народа позиций как на международной арене (особенно в Восточной Европе), так и внутри страны. Практически одномоментно лишившись экономики из-за ликвидации Госплана и отмены госзаказа, из-за разрушения цепочек поставок сырья и готовых изделий и героической истории предыдущих поколений народов России во главе с русским из-за целенаправленно хлынувшего из СМИ потока лжи, а также в связи с катастрофическим ослаблением армии и флота из-за пренебрежения нуждами Вооруженных сил руководством страны, Россия оказалась к началу нулевых годов на грани выживания как государство. К тому же она столкнулась с чеченским сепаратизмом и международным терроризмом, почти открыто поддерживаемыми Западом во главе с США 1 .

Окончательное осознание необходимости укрепления обороноспособности страны и защиты от «западных друзей» пришло после начала расширения НАТО на восток (12.03.1999), и особенно после бомбардировки Союзной Республики Югославия (23.03. - 10.06.1999), когда, почувствовав полнейшую безнаказанность, западный мир, назначив виновными во всем сербов, начал перекраивать Балканы. Из-за бомбардировки славянского народа и невозможности оказания ему помощи народ России испытал большое унижение и окончательно разочаровался в западной демократии, насаждаемой путем разрушения инфраструктуры, промышленности и культурных объектов. Показательно разбомбить Белград, отобрать Косово, пренебречь международным правом позволила соглашательская политика руководства Советского Союза и России.

\footnotetext{
1 Меликов В. Экспорт терроризма из Сирии: боевики ИГИЛ с помощью США могут начать войну на территории бывшего СССР. 20.02.2019. Доступ: https://riafan.ru/1153141-eksport-terrorizma-iz-siriiboeviki-igil-s-pomoshyu-ssha-mogut-nachat-voinu-na-territorii-byvshego-sssr (проверено 04.07.2019).
} 
Со слабыми Запад не считается, да и не считался никогда, принуждая силой к «демократии», подразумевающей полное подчинение вплоть до разрушения государственности и раздробления с целью ограбления и отъема сырья, что затем было продемонстрировано в Ираке и Ливии. Приблизительно что-то подобное ожидало и Россию. Возможно, без применения военной силы, а как первая демократизация в 1990-х по лекалам «вашингтонского обкома», проведенная под видом реформ, приведшая к практически полной утере станко-, авиа-, и судостроения и многих других высокотехнологичных отраслей промышленности. Единственная оставшаяся без «реформирования» атомная промышленность сейчас одна из лучших в мире.

Для населения России последствия превращения в сырьевой придаток Запада оказались катастрофичными. Выбросив на рынок услуг из сферы производства сотни тысяч высококвалифицированных специалистов и рабочих, лишив их надежды найти работу в условиях жесткой конкуренции, руководство России, занятое дележом наследства СССР, своему народу «шоковой терапией» нанесло ущерб, сравнимый с потерями в Великой Отечественной войне, а из-за продолжающейся неуверенности в будущем у значительной части населения возможно, и бо́льшие потери. После войны у народов СССР был социальный оптимизм, основанный на доступности работы, жилья, образования, здравоохранения, достижений многонациональной культуры, уверенности в лучшем будущем. Этим объясняется послевоенный бум рождаемости, несмотря на понесенные страной потери. Такое стремительное скатывание по всем направлениям, случившееся без эпидемий, климатических катастроф, внешней военной агрессии, какое произошло с Россией в 1990-х, можно назвать только контрреволюцией, т.к. революция подразумевает скачок вперед.

В 2004 г. пятое, самое масштабное расширение НАТО, связанное с приемом Эстонии, Латвии, Литвы, Румынии, Болгарии и Словении (позднее министр обороны США скажет: «Россия стоит на пороге НАТО»), и замена концепции HАTO на защиту от возможной агрессии России определили для России основную внешнюю угрозу - Североатлантический блок, т.к. основные территориальные споры с нашим восточным соседом были разрешены, а в международных отношениях позиции России и Китая часто совпадали. На Мюнхенской конференции по безопасности в 2007 г. В.В. Путин напомнил цитату из выступления генсека НАТО в Брюсселе 17 мая 1990 г:: «Сам факт, что мы готовы не размещать войска НАТО за пределами территории ФРГ, дает Советскому Союзу твердые

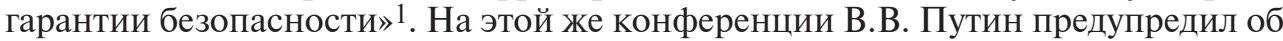
опасности однополярного мира как для всего мира, так и для самих США, т.к. он разрушает их изнутри, порождая ничем не сдерживаемое, гипертрофированное применение военной силы в международных делах, ввергающее мир в пучину следующих один за одним конфликтов. В.В. Путин напомнил: «Россия - страна с более чем тысячелетней историей, и практически всегда она пользовалась привилегией проводить независимую внешнюю политику. Мы не собираемся изменять этой традиции и сегодня» ${ }^{2}$. Этим отказом выполнять рекомендации и требования извне Россия навлекла на себя открытый гнев Запада, который целенаправленно стал устраивать провокации (война в Грузии, Болотная площадь), а также устроил националистический переворот на Украине и сделал ее полуколонией с целью развязывания войны и уничтожения русских самими русскими. Збигнев Бжезинский, самый оголтелый русофоб, предрекал: «Новый

\footnotetext{
1 Выступление и дискуссия на Мюнхенской конференции по вопросам политики безопасности. Доступ: http://kremlin.ru/events/president/transcripts/24034 (проверено 15.04.2019).

2Там же.
} 
мировой порядок при гегемонии США будет строиться против России, на руи-

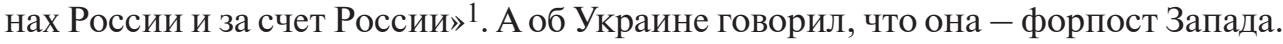
О том, что дружба России с англосаксами невозможна, что они всегда будут искать повод для нанесения вреда, мешать развитию и будут пытаться удушить любыми способами, говорилось в выступлении президента США Б. Клинтона на заседании Комитета начальников штабов вооруженных сил страны 24 октября 1995 г. (в период большой дружбы с Б. Ельциным): «...в ближайшее десятилетие предстоит решение следующих проблем:

1. Расчленение России на мелкие государства путем межрегиональных войн подобных тем, что мы организовали в Югославии.

2. Окончательный развал военно-промышленного комплекса России и армии.

3. Установление в республиках, оторвавшихся от России, нужных нам режимов» ${ }^{2}$.

Сейчас, когда Запад почувствовал угрозу своей гегемонии со стороны Китая и России, понимая, что Китай без предварительной победы над Россией ему не остановить, были включены беспрецедентные меры давления на все точки развития экономики России, открыто ведется информационная и санкционная война по откровенно надуманным поводам без всяких доказательств (вмешательство в американские выборы, мифическое отравление Скрипалей) с целью очернения России. Штаты и Великобритания выделяют огромные средства и создают организации для провокаций против России, в т.ч. и в киберпространстве. Из опыта последних 30 лет можно заключить: если Запад хвалит, то у нас все плохо, а если выступает с нападками - значит, у России дела налаживаются. Оглядываясь назад, можно представить, с чем столкнулся избранный в 2000 г. президентом России В.В. Путин, какие многоуровневые задачи пришлось ему решать как внутри страны, так и вне ее, начиная с замирения Чечни, выстраивания вертикали власти (после ельцинского: «берите суверенитета столько, сколько проглотите»), принуждения к миру Грузии после ее агрессии в Южной Осетии. Скрытно проведенное реформирование и перевооружение Вооруженных сил РФ позволило воссоединиться с Крымом и поддержать Донбасс без желаемого Западом ввода войск, в самый ответственный момент оказать помощь Сирии против агрессии ИГИЛ (запрещена в России) - взрашенной и поддерживаемой США группировки ${ }^{3}$, которую после Сирии Штаты могли направить на расшатывание ситуации на Кавказе, в Средней Азии и Поволжье.

Предупреждение В.В. Путина, что в случае агрессии против Российской Федерации она ударит не только по проявившим агрессию, но и по центру принятия решений об агрессии, вероятно, повлияло на отказ Берлина и Парижа участвовать в провокациях в Керченском проливе, несмотря на давление Вашингтона, а также, вероятно, повлечет за собой усиление расшатывания ситуации внутри нашей страны и усиление поддержки внутренней «пятой колонны». В доказательство того, что внутренний враг - самый опасный, можно привести цитаты американцев. Бывший госсекретарь США Джеймс Бейкер о гибели СССР: «Мы истратили триллионы долларов за последние сорок лет, чтобы одержать победу в холодной войне против СССР. Главное, нашлись

\footnotetext{
1 Умер Збигнев Бжезинский. Доступ: https://esquire.ru/articles/21462-zbigniew-brzezinski/ (проверено 15.04.2019).

2 Речь Б. Клинтона на закрытом совещании Объединенного комитета начальников штабов 25 октября 1995. Доступ: http://maxpark.com/community/politic/content/1750551 (проверено 04.07.2019).

3 Сивков К. США взрастили ИГИЛ и «Хорасан». Доступ: https://www.russiapost.su/archives/33806 (проверено 15.04.2019); Захаров Р. В МИД РФ нашли доказательства связей США с ИГИЛ. 16.01.2019. Доступ: https://tvzvezda.ru/news/vstrane_i_mire/content/201901161801-u4s7.htm (проверено 18.04.2019).
} 


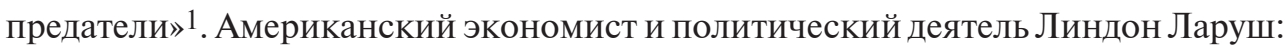
«В Советском Союзе есть люди, которых можно квалифицировать не иначе, как предатели Советского Союза. Они связаны с Великобританией. Большинство из них учились в Англии. С середины восьмидесятых их учила английская разведка. И сегодня они занимают в России ключевые, исключительные посты» 2 . Особенно актуальны в нынешнее время слова Роберта Гейтса, директора ЦРУ в 1991-1993 гг., напечатанные в «Известиях» 12 декабря 1991 г.: «Мы понимали, что Советский Союз ни экономическим давлением, ни гонкой вооружений, ни тем более силой не возьмешь. Его можно было разрушить только взрывом изнутри».

В указе Президента РФ № 683 от 31.12.2015 «О стратегии национальной безопасности» перечислены все угрозы существования России, как внешние, так и внутренние. Их анализ, а также исторический опыт существования России говорят, что решающая угроза - внутренняя, часто привнесенная извне, но использующая предательство элиты, просчеты в руководстве страной, несправедливость в дележе природных богатств, откровенный грабеж страны с вывозом капитала за рубеж, вседозволенность чиновничества, сращивание власти и правоохранителей с криминалом, разграбление бюджета для подъема недовольства населения, посева хаоса и разрушения государственности посредством революции. Предпосылки для нее имеются. Об этом говорится в статье «Такое неравенство в последний раз было перед революцией» в журнале «Вольная экономика» [Тетерятников 2018]. Российский народ устал от революций, реформ, перестроек и пока терпит даже явное ущемление прав, как в случае отмены нищенской индексации у работающих (из-за нищеты) пенсионеров, так и повышения возраста выхода на пенсию (при большой численности людей, и прежде не доживавших до нее). Как пишет Руслан Хубиев, «наибольшие спады в развитии, как по глубине, так и по продолжительности в истории России приходились отнюдь не на войны, а именно на периоды революций. Тысяча девятьсот семнадиатый, тысяча девятьсот девяносто первый, и наконец несостоявшийся две тысячи двенадиатый» [Хубиев 2016]. От 1991 г. Россия не может оправиться до сих пор.

Внимание к внутреннему социальному экономическому развитию сосредоточено в Послании Президента РФ В.В. Путина Федеральному собранию РФ от 20 февраля 2019 г., и особенно выделена ключевая задача: сбережение народа, всемерная поддержка семей, а также избавление от бедности, решение проблем здравоохранения и экологии. В своей речи В.В. Путин подчеркнул: «Россия была и будет суверенным, независимым государством. Это просто аксиома. Она будет либо такой, либо вообще ее не будет. Для всех нас это должно быть понятно, мы должны это понимать и осознавать. Россия не может быть государством, если она не будет суверенной. Некоторые страны могут, Россия - нет» 3 .

В заключение хочется привести слова Джорджа Буша-старшего. В интервью в 1992 г. он сказал слова, которые, хочется надеяться, близки к истине: «Россия и Союз как матрешки. Они были вложены друг в друга. В реальности мы соревновались с Россией, но она была в виде Союза, то есть на ногах у нее были огромные гири. Сейчас эти гири при распаде Союза убраны. Россия преодолеет свои нынешние проблемы и станет гораздо более злой и могучей

\footnotetext{
${ }^{1}$ Госсекретарь США о гибели СССР: «Главное, нашлись предатели». Доступ: https://politikus.ru/ articles/politics/5865-gossekretar-ssha-o-gibeli-sssr-glavnoe-nashlis-predateli.html (проверено 15.04.2019).

2 Линдон Ларуш: Горбачев и Чубайс подготовлены английской разведкой. Доступ: http://rusmi.su/ news/04-2015/news182.html (проверено 15.04.2019).

3 Послание Президента РФ Федеральному Собранию. Доступ: http://kremlin.ru/events/president/ news/59863 (проверено 15.04.2019).
} 
и хорошо запомнит всех, кто ее нынче обидел» ${ }^{1}$ Хотя такой обвал, какой случился уже после его слов, мог реально разрушить Россию в сроки, близкие к поставленным Б. Клинтоном. Россия свалилась в пропасть дефолта, достигла «дна» и «пробила его», но выстояла и заявила о себе на международной арене. В интервью «Российской газете» и ТАСС Генри Киссинджер сказал: «Россия и США должны проявить взаимоуважение и продолжать сотрудничество. 〈...> Мне трудно представить международный порядок, в котором Россия не будет в числе крупных игроков» ${ }^{2}$.

У России на данном этапе существования, на мой взгляд, нет настоящих друзей. Есть сочувствующие, есть попутчики, есть наблюдатели, но готовых чем-либо поступиться, не говоря уже о самопожертвовании, не наблюдается. Может, это и к лучшему. Лев Николаевич Толстой говорил: «Трусливый друг страшнее врага, ибо врага опасаешься, а на друга надеешься» 3 . Но другое его выражение: «Есть только один способ положить конец злу - делать добро злым людям» ${ }^{4}$. В современных условиях пример России всей своей новейшей драматической историей, начавшейся с игры в поддавки и чуть не окончившейся, как у Югославии, показывает, что злу надо противиться так, чтобы агрессор знал, что в современной войне победителей не будет, какие стратегии он ни применяй. Можно привести высказывание В.В. Путина на заседании международного дискуссионного клуба «Валдай» в октябре 2018 г. об агрессорах: «Мы как мученики попадем в рай, а они просто сдохнут. Потому что они даже раскаяться не успеют»5.

Российский народ, обманутый не единожды в своем стремлении к справедливости, сейчас, после того как государство укрепило свою защиту от внешних посягательств, вправе рассчитывать на ускорение экономического, а следовательно и социального развития и, наконец-то, получить 25 млн высококвалифицированных рабочих мест на материальном производстве, чтобы жить созидательной жизнью.

\section{Список литературы}

Тетерятников К. 2018. Такое неравенство в последний раз было перед революцией. - Вольная экономика. 29.11. Доступ: http://freeconomy.ru/themes/ socpol/takoe-neravenstvo-v-poslednij-raz-bylo-pered-revolyutsiej.html (проверено 04.07.2019).

Хубиев Р. 2016. Гроссмейстер Путин [грандиозная многоходовка длиной в 16 лет]. 13 мая. Доступ: https://cont.ws/@barbera/269818 (проверено 04.07.2019).

\footnotetext{
1 Интервью Буша-старшего в 1992 году! Доступ: https://politikus.ru/events/45653-intervyu-bushastarshego-v-1992-godu.html (проверено 04.07.2019).

2 Гусман М. Без России нет порядка. - Российская газета. 26.03.2019. Доступ: https://rg.ru/2019/03/26/ genri-kissindzher-rossiia-i-ssha-dolzhny-proiavit-vzaimouvazhenie.html (проверено 04.07.2019).

3 Лев Николаевич Толстой. Доступ: https://antrio.ru/lev-nikolaevich-tolstoj-citaty/ (проверено 15.04.2019).

4 Там же.

5 Путин на «Валдае» о ядерной войне: мы в рай, а они просто сдохнут. Доступ: https://www.bbc.com/ russian/news-45905674 (проверено 07.04.2019).
} 
KRASINA Evgeniya Aleksandrovna, Senior Lecturer of the Chair of the English Language, Faculty of World Economy, Diplomatic Academy of the Ministry of Foreign Affairs of Russia (53/2 Ostozhenka St, Moscow, Russia, 119021; lizzasun@mail.ru)

\title{
ROLLER COASTER FOR RUSSIA: IT IS NECESSARY TO WITHSTAND EXTERNAL AND, MOST IMPORTANTLY, INTERNAL THREATS
}

Abstract. The conciliatory foreign and catastrophic domestic economic policies of the leadership of the USSR, and then of Russia, led to a significant reduction in the population, and put the state itself on a waiting list for the destruction by the North Atlantic Alliance led by the United States according to the Yugoslav scenario. The straight forwardly degrading policy of the West showed the new leadership of Russia, who wanted equal cooperation in all spheres, the absence of the desire of the West to go forward. The answer to the expansion of NATO to the borders of Russia was the reform of the armed forces, which was carried out so effectively that it allowed to help Crimea in returning to the state and enabled the allied Syria to succeed in combating the aggression of international terrorism supported by the United States. The internal enemy, on the side of which play the leadership mistakes, corruption, permissiveness of officials, merging of authorities with crime, etc., is the most dangerous one, as evidenced by all the recent history of Russia. Therefore, it is important not to create occasions for feeding the false defenders of the people of Russia with unsightly facts, and most importantly, it is necessary to restore social equity and provide the population with well-paid skilled jobs.

Keywords: policy of betrayal of Russia's interests, Russian economy, aggressive policy of the west, NATO, strategy of defense and development of Russia

ГРИБОВ Роман Викторович - соискатель кафедры истории, философии, политологии и социологии Саратовского социально-экономического института (филиала) Российского экономического университета им. Г.В. Плеханова (410003, Россия, г. Саратов, ул. Рaдищева, 89; kafedra_epir@ssea. runnet.ru

\section{РАЗВИТИЕ НЕФТЕГАЗОВОЙ ПРОМЫШЛЕННОСТИ В УСЛОВИЯХ НЕБЛАГОПРИЯТНОЙ ГЕОПОЛИТИЧЕСКОЙ ОБСТАНОВКИ: ИСТОРИЧЕСКИЙ ОПЫТ И СОВРЕМЕННОСТЬ}

\begin{abstract}
Аннотация. В статье анализируется проблема обеспечения нефтегазовой отрасли отечественным оборудованием в условиях санкций со стороны зарубежных партнеров. Автор изучает факторы влияния геополитической обстановки в мире на развитие добывающих отраслей экономики и на историческом примере показывает, как санкционная политика США в отношении СССР привела к тому, что отечественная наука совершила прорыв в создании качественных образцов оборудования и техники для стабильного функционирования нефтегазового комплекса, обеспечив высокую физическую и моральную долговечность основных фондов.
\end{abstract}

Ключевые слова: наука, санкции, импортозамещение, инвестиции, модернизация, отечественное нефтегазовое оборудование

B о второй половине XX - начале XXI в. основными тенденциями развития мировой экономики стали интеграция и глобализация. Несомненно, тесное 